\title{
Synthesis and Bactericidal Properties of Hyaluronic Acid Doped with Metal Nanoparticles
}

\author{
Galo Cárdenas-Triviño, ${ }^{1}$ Macarena Ruiz-Parra, ${ }^{2}$ Luis Vergara-González, ${ }^{3}$ \\ Javier Ojeda-Oyarzún, ${ }^{4}$ and Guillermo Solorzano ${ }^{5}$ \\ ${ }^{1}$ Facultad de Ingeniería, Centro de Biomateriales y Nanotecnología, Universidad del Bío-Bío, Av. Collao 1202, Concepción, Chile \\ ${ }^{2}$ Facultad de Ciencia, Química y Farmacia, Universidad San Sebastián, Lientur 1457, Concepción, Chile \\ ${ }^{3}$ Facultad de Ciencia, Departamento de Ciencias Biológicas y Químicas, Universidad San Sebastián, Lientur 1457, Concepción, Chile \\ ${ }^{4}$ Facultad de Medicina Veterinaria, Universidad Austral de Chile, Independencia 641, Valdivia, Chile \\ ${ }^{5}$ Departamento de Engenharia Química e de Materiais, Pontifical Catholic University of Rio de Janeiro, \\ R. Marquês de São Vicente 225, Gávea, Rio de Janeiro, RJ, Brazil
}

Correspondence should be addressed to Galo Cárdenas-Triviño; gcardenas@ubiobio.cl

Received 23 March 2017; Accepted 9 October 2017; Published 17 December 2017

Academic Editor: Raul Fangueiro

Copyright ( 2017 Galo Cárdenas-Triviño et al. This is an open access article distributed under the Creative Commons Attribution License, which permits unrestricted use, distribution, and reproduction in any medium, provided the original work is properly cited.

\begin{abstract}
A study on the nanoparticles size and the antibacterial properties of hyaluronic acid (HA) doped with nanoparticles is reported. Nanoparticles from gold, silver, copper, and silver palladium with HA support were performed. The solvated metal atom dispersion (SMAD) method with 2-propanol and HA was used. High-resolution transmission electron microscopy (HRTEM), infrared spectroscopy (FT-IR), and thermogravimetric analysis (TGA) were conducted. The average sizes of nanoclusters were as follows: $\mathrm{HA}-\mathrm{Au}=17.88 \mathrm{~nm} ; \mathrm{HA}-\mathrm{Ag}=50.41 \mathrm{~nm} ; \mathrm{HA}-\mathrm{Cu}=13.33 \mathrm{~nm}$; and HA-AgPd $=33.22 \mathrm{~nm}$. The antibacterial activity of solutions and films containing nanoparticles against American Type Culture Collection (ATCC) bacterial strains Escherichia coli (EC), Staphylococcus aureus (SA), Staphylococcus epidermidis (SE), and Pseudomonas aeruginosa (PA) was determined. Inhibition was observed for HA-Ag, HA-Cu, and HA-AgPd. Toxicological tests were performed in rats that were injected intraperitoneally with two concentrations of gold, copper, silver, and silver-palladium nanoparticles. No alterations in hepatic parameters, including ALT (alanine aminotransferase), GGT (gamma-glutamyl transpeptidase) bilirubin, and albumin, were observed after 14 days. These films could be used as promoters of skin recovery and Grades I and II cutaneous burns and as scaffolds.
\end{abstract}

\section{Introduction}

Nanotechnology is now one of the highest priorities in science and technology research [1]. By controlling the size, shape, and distribution of nanoparticles (NPs), it is possible to determine their properties and the nature and intensity of their interactions with other molecules. One way to modify the final properties of a nanomaterial is to use a polymeric support. The unique properties of supported metallic nanoparticles (MNPs) are directly related to the types of particles (size and shape), the dispersion, concentration, and electronic properties of the metal in the support [2,3]. MNPs dispersed in solvents have been widely studied over the past few years because their properties have enabled applications in the areas of electronics, medicine, environmental science, and materials science [4].

Nanomedicine is a field that encompasses applied nanotechnology methods in medicine. Thus, it allows the use of nanotechnology in cutting-edge research that will lead to the creation of better techniques for the treatment of diseases to improve the prognosis of patients [5]. The revolutionary aim of this science is focused primarily on monitoring, repairing tissue, controlling the evolution of disease, and defending and improving human biological systems. The most significant biotechnological advances in this field include biosensors, novel pharmacoselective agents, and the development of materials for grafts, among others [6]. 
The antimicrobial activity of metal nanoparticles had been reported profusely in the last years [7-10] as a possible alternative treatment for infected wounds, particularly with antimicrobial resistant bacteria, and nanoparticles of various metals have been studied.

There is evidence that demonstrates that gold nanoparticles are inert or have nontoxic effect on human cells [11]. No proinflammatory cytokines secretion, such as necrosis factor tumor alpha (TNF- $\alpha$ ), was detected in a study with macrophage cells; these results emphasize that AuNPs are not cytotoxic or immunogenic but are biocompatible, corroborating their excellent potential in the areas of nanoimmunology, nanobiotechnology, and nanomedicine [12]. On the other hand, good antibacterial activity has been demonstrated against various pathogenic bacteria $[13,14]$.

In contrast to gold nanoparticles, silver nanoparticles (AgNPs) show toxicity associated with their oxidative and inflammatory nature [15], which is related to their genotoxicity and cytotoxicity $[16,17]$. Therefore, it is suggested that AgNPs can inhibit the mechanisms of antioxidant defense through the reduction of glutathione, inactivation of the superoxide dismutase, and promotion of lipid peroxidation [18]. Consequently, reactive oxygen species accumulation and oxidative stress can cause many physiological and cellular events, including stress, disruption and destruction of mitochondria, apoptosis, inflammation, and damage to DNA [19]. The mitochondria appear to be the cellular compartment most sensitive to the toxicity of AgNPs [20].

In addition to the damage to DNA and mitochondria, it has also been observed that AgNP exposure, in contrast with AuNPs, induces the release of a series of proinflammatory markers, predominantly TNF- $\alpha$, pulmonary intravascular macrophages, and granulocyte colony-stimulating factor [21]. However, the toxicity of AgNPs is still a concern matter because AgNPs release $\mathrm{Ag}^{+}$ions in aqueous solution [22], and there is evidence that the silver ion presence enhances significantly the toxicity of AgNPs [23].

On nanoscale, pure copper or copper oxides become even more toxic to pathogenic microorganisms, an effect that is directly related to the size of the particles. As is the case with other metals, the presence of excess copper has also been proven to be toxic, to a certain extent, to cellular organisms in general $[24,25]$. This is because, in the presence of water and oxygen, copper releases positive ions and generates hydroxyl radicals, both of which are highly toxic. In addition, the electrons produced by oxidation reactions interact with water molecules, forming other hydroxyl radicals [26, 27].

There are multiple effects that show the toxicity of copper: (1) inhibition or alteration of protein synthesis; (2) alterations to the permeability of the cell membrane, causing the peroxidation of lipids by inducing oxidative damage to them; as a result, an imbalance is created in the entrance and the exit of minerals, including sodium and potassium, that are essential for normal cells to function; and (3) destruction or alteration of nucleic acids (DNA), thus disrupting the ability of cells to multiply [28].

In a study that evaluated the in vitro toxicity of CuNPs in fibroblast cells from mouse embryos showed that $\mathrm{Cu}^{2+}$ ions are more cytotoxic than covered NPs (CuNPs) [26] as has been reported also for AgNPs and silver ions.

Palladium has been used in alloy with gold, silver, and tin as a material for dental restoration for years, and health concerns about his use are due it known effect on the immune system $[29,30]$. Limited other data about palladium toxicity has been reported [31]. For this reason, AgPd-NPs was included in this study.

Hyaluronic acid (HA) is a fundamental component of the extracellular matrix of the skin, mucosal tissue, joints, eyes, and many other organs and tissues. It is involved in tissue repair processes and is an essential component in the resurfacing of the skin and the prevention of scar formation. Its osmotic capability restores tissue hydration during the inflammatory process, and its viscosity helps to prevent the passage of bacteria and viruses into the pericellular area (around the cell). It is a known stimulator of the inflammatory process because it acts as a barrier to tissue degradation and has antioxidant properties, including the ability to eliminate free radicals [32-34], which are tissue-damaging byproducts derived from the metabolism of oxygen that can cause inflammation and cancer [35].

HA, is a potent water attractant. This property provides hydration, firmness, smoothness, and a defensive barrier to the skin and also offers mechanical stability to joints and slows down skin aging.

The main goal of this work is to obtain films of HA doped with MNPs to improve skin recovery and to control bacterial infections of wounds.

\section{Materials and Methods}

2.1. Metal Atom Reactor (Chemical Liquid Deposition-Solvated Metal Atom Dispersion Method). The metal atom reactor used has been previously described [36, 37]. In a typical procedure, an alumina-tungsten crucible at the bottom of the reactor was charged with $0.150 \mathrm{~g}$ of Au metal and $3.0 \mathrm{~g}$ of HA. Dry 2-ethoxyethanol was placed in a ligand inlet tube and degassed by several freeze-pump-thaw cycles. The reactor was pumped down to 0.008 mbar, while the crucible was heated until it was red. A liquid nitrogen-filled Dewar was placed around the vessel, and Au and 2-ethoxyethanol (70 ml) were deposited over a period of $1 \mathrm{~h}$ with a current of $35 \mathrm{~A}$. The matrix was a blue/purple color at the end of the deposition. The matrix was then allowed to warm slowly under vacuum for $1 \mathrm{~h}$ by removing the liquid nitrogen Dewar. Upon meltdown, a purple colloid was obtained. After returning the matrix to $1 \mathrm{~atm}$ by the addition of nitrogen, the colloid was allowed to warm for another $0.5 \mathrm{~h}$ at room temperature. The dispersion was stirred for $12 \mathrm{~h}$ and was then syphoned out under nitrogen into a flask. Based on the evaporated metal and 2-ethoxyethanol in the inlet, the molarity of the metal could be calculated. Several concentrations were prepared under the same conditions for $\mathrm{Ag}, \mathrm{Cu}$, and $\mathrm{AgPd}$ (between 50 and $200 \mathrm{mg}$ ). No hydrogen evolution during the metal evaporation was observed. The vacuum remained constant during the evaporation process. 
2.2. Metallic Solids. Metallic solids were prepared by the direct evaporation of solvent, achieved by connecting the receiver flask to the vacuum line for a period of approximately $10 \mathrm{~h}$. Once the solvent had evaporated, the flask and the solid could be collected, after which it was stored in a dry chamber under atmosphere of nitrogen gas to prevent the oxidation of the material.

\subsection{High-Resolution Transmission Electron Microscopy} (HRTEM). Micrographs were obtained on a JEOL 2100F high-resolution transmission electron microscope $(200 \mathrm{kV})$ or on a JEOL $2010 \mathrm{TEM}(200 \mathrm{KV})$. It was possible to determine the range of size distribution of NPs in addition to possible distortions and imperfections in the MNPs of Au, $\mathrm{Ag}, \mathrm{Cu}$, and the alloy AgPd. Sample preparation included a procedure that separated and dissolved the polymer nanoparticles using only HA and water as solvent. This step allowed us to view the NPs in more detail. In this procedure, solid polymer containing MNPs and weighing approximately $0.002 \mathrm{~g}$ to $0.008 \mathrm{~g}$ was dissolved in 3 or $6 \mathrm{ml}$ of sterile distilled water and sonicated for 15 minutes; then, 1 drop of the solution obtained was placed in the grid of copper or nickel with a carbon film. The average particle size was obtained from 59 measurements.

\subsection{Infrared Spectroscopy with Fourier Transform (FT-IR).} The spectrophotometer used to obtain IR spectra was a Nicolet Magna 500 equipped with Nicolet EZ OMNIC software for the collection and analysis of spectra.

The sample preparation method used most often for the analysis of solid samples involved a $\mathrm{KBr}$ matrix; specifically, the solid samples were dispersed and supported on a $\mathrm{KBr}$ matrix tablet. For the preparation of the tablet, solid fiberglass $(1 \mathrm{mg})$, previously cut with a microtome, was dispersed on an array of $\mathrm{KBr}(100 \mathrm{mg})$ by mixing and grinding to homogenize the mixture inside an agate mortar. Then, the mixture was introduced into a mold and compressed to obtain a disc. Subsequently, the disc was stored in a desiccator until FT-IR analysis.

Spectra were recorded in a wavelength range from $400 \mathrm{~cm}^{-1}$ (25 micrometers) to $4000 \mathrm{~cm}^{-1}$ (2.5 micrometers), which defined the IR electromagnetic radiation spectrum. The analysis included obtaining the far and middle IR spectra of each of the samples.

2.5. Thermogravimetric Analysis (TGA). Thermogravimetry was performed with a Q50 V2010 Build 36 TGA. Samples of the solid were heated at a rate of $10^{\circ} \mathrm{C} / \mathrm{min}$ in air with a flow rate of $20 \mathrm{ml} / \mathrm{min}$. From the corresponding thermogram, the temperature of decomposition and the mass percent composition of the degradation products were determined.

2.6. Microbiological Tests. For the bacteriological assays, four bacterial strains were used: Escherichia coli (ATCC 25922), Pseudomonas aeruginosa (ATCC 27853), Staphylococcus aureus (ATCC 25923), and Staphylococcus epidermidis (ATCC 12228).
The antibacterial properties of the NPs supported in HA were assayed by a qualitative approach. For this, a $1 \mathrm{~cm}^{2}$ film prepared from HA and the appropriate NPs was deposited in a Petri dish containing a thin layer of Mueller-Hinton $(\mathrm{MH})$ agar. Then, $10 \mathrm{ml}$ of $\mathrm{MH}$ agar containing an inoculum of approximately $10^{6} \mathrm{CFU} / \mathrm{ml}$ was poured onto the film until it was covered. The antibacterial activity was determined by comparing the growth to that of a control film without NPs.

2.7. Toxicological Test: Bioassays in Rats. The experimental method of intraperitoneal injection in mice started with a full physical examination of the rats before beginning the administration of the solutions under study. The average temperature, pulse, and breathing needed to be $38^{\circ} \mathrm{C}, 280$ beats $/ \mathrm{min}$, and 90 breaths/min, respectively, before proceeding. The animals were supplied with adequate food and water, in addition to controlling the conditions in terms of light and humidity. Ether was used as an anesthetic; before the induction, the rats were fasted for at least $12 \mathrm{~h}$. This procedure employed all possible hygienic measures, such as the use of surgical gloves, apron, cap, and mask. Once the mouse was sedated, it was held during injection of the solution under study using a syringe that conformed to the desired volume level. The solution was injected into the back of the mouse, around the cervical area.

After the solutions were administered, all the rats under study, including the control group, were maintained under conditions with adequate food, light, temperature, and humidity until the day established as the end of the analysis, at which point a number of rats in each group under study were sacrificed. For example, a rat from each group was analyzed in terms of their liver enzymes to determine toxicity in the long and short term.

The studies that were performed in the present work were conducted, without exception, while respecting international standards for the management of laboratory animals according to National Institute of Health Guide for the Care and Use of Laboratory Animals and the Bioethics Committee (Universidad Austral de Chile).

\section{Results}

3.1. High-Resolution Transmission Electron Microscopy (HRTEM). From the micrographs (Figure 1(a)) obtained, it is possible to observe atomic planes previously reported in the literature for each NP. Using Digital Micrograph software, measurements of interplanar spacing values were performed to identify the type of atomic plane. From these data, it is possible to determine the space between each interplanar layer of the metallic element $(0.39 \mathrm{~nm})$ and that the MNPs have a face-centered cubic (fcc) crystal structure. One of the objectives of this TEM analysis was to determine the size distribution of the MNPs under study and to determine the presence or absence of any distortions or imperfections in the particles arising from an incomplete synthesis process.

Assuming that its crystalline structure is fcc on both sides, the measurement of the extent of the interplanar distance is 


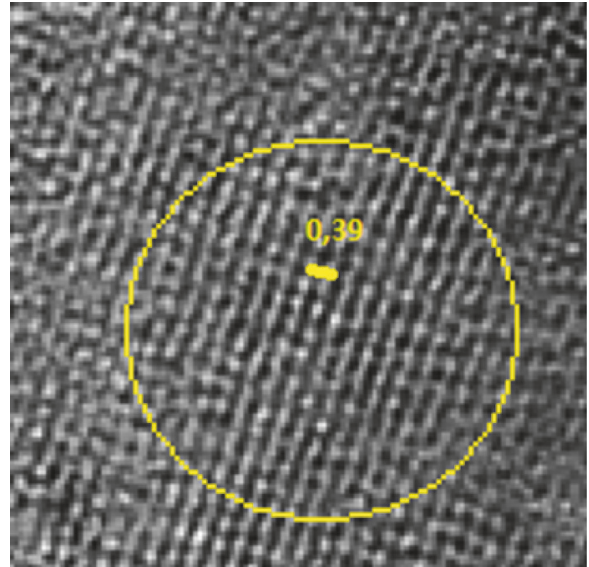

(a)

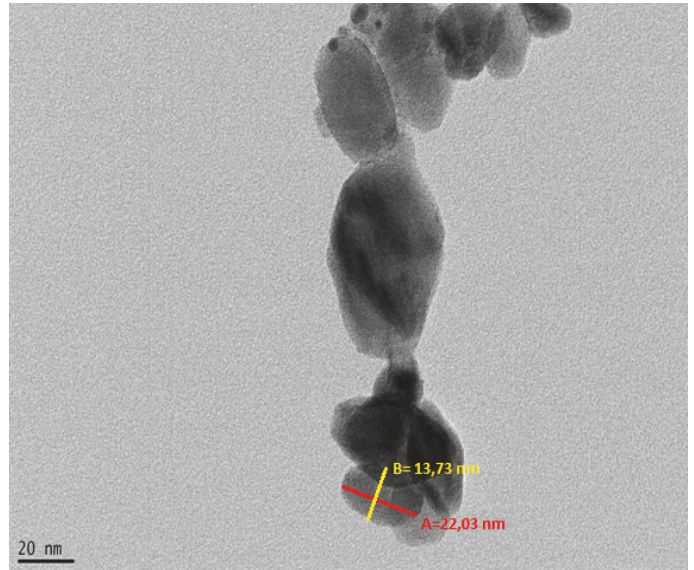

(b)

FIGURE 1: (a) High-resolution micrograph of HA-Au-2. Interplanar distance $=0.39 \mathrm{~nm}$. (b) Micrograph exhibiting Au NP supported in HA with an average particle size of $17.88 \mathrm{~nm}$.

TABLE 1: Frequency bands of the major functional groups present in the HA and HA + metal NPs.

\begin{tabular}{|c|c|c|c|c|c|c|}
\hline Number & Bond & $\begin{array}{c}\text { Frequency }\left(\mathrm{cm}^{-1}\right) \\
\text { pure HA }\end{array}$ & $\begin{array}{c}\text { Frequency }\left(\mathrm{cm}^{-1}\right) \\
\mathrm{HA}+\mathrm{Au}-2\end{array}$ & $\begin{array}{c}\text { Frequency }\left(\mathrm{cm}^{-1}\right) \\
\mathrm{HA}+\mathrm{Ag}-2\end{array}$ & $\begin{array}{c}\text { Frequency }\left(\mathrm{cm}^{-1}\right) \\
\mathrm{HA}+\mathrm{Cu}-2\end{array}$ & $\begin{array}{c}\text { Frequency }\left(\mathrm{cm}^{-1}\right) \\
\mathrm{HA}+\mathrm{AgPd}-2\end{array}$ \\
\hline (1) & $\nu \mathrm{O}-\mathrm{H}$ & 3428,52 & 3419,14 & 3431,03 & 3430,83 & 3426,44 \\
\hline (2) & $\nu \mathrm{C}-\mathrm{H}$ & 2928,61 & 2926,71 & 2914,37 & 2925,68 & 2922,69 \\
\hline (3) & $\nu \mathrm{C}=\mathrm{O}$ & 1624,47 & 1728,94 & 1629,23 & 1630,56 & 1623,40 \\
\hline (4) & $\nu \mathrm{C}-\mathrm{C}$ & 1414,42 & 1412,76 & 1416,64 & 1417,31 & 1415,47 \\
\hline (5) & $\nu \mathrm{C}-\mathrm{C}$ & 1326,19 & 1281,01 & 1316,18 & 1319,27 & 1321,25 \\
\hline (6) & $\nu \mathrm{C}-\mathrm{O}$ & 1154,97 & - & - & 1155,23 & 1154,67 \\
\hline (7) & $\nu \mathrm{C}-\mathrm{O}$ & 1041,64 & 1077,03 & 1043,18 & 1042,60 & 1039,55 \\
\hline (8) & $\delta \mathrm{CH}_{2}$ & 611,40 & 611,01 & 604,97 & 606,98 & 613,01 \\
\hline (9) & $\nu \mathrm{C}=\mathrm{O}$ & - & 1618,63 & - & - & - \\
\hline
\end{tabular}

equal to $0.362 \mathrm{~nm}$. It can be concluded that the observed plane is the (111) plane.

The quality of the two high-resolution images in Figure 3 of the silver-palladium (alloy) NPs should be noted; it is possible to see at a glance atomic levels, interplanar distances, and facets of the location of the atoms. Clearly, the observation of the spatial arrangement of atoms in the more stable (111) plane was achieved.

The shape of the NPs was generally not a perfect sphere, so, the average size was calculated as the mean of the width and the length of several particles (see Figure 4).

According to measurements made using Digital Micrograph software, the sizes of the gold, silver, copper, and silverpalladium MNPs were within the range of $10-50 \mathrm{~nm}$.

Based on the results obtained and the micrographs shown above, it is possible to determine that the sizes of the different types of NP, for example, Au and Ag NPs, are not homogeneous, which is to be expected because, during the synthesis process, unequal amounts in terms of milligrams of metal not used in the formation reaction lead to different particle sizes at the nanometer scale. However, it was not expected that there would be a difference in the distribution of sizes between a single type of metal NP, for example, silver, in which case there were no more than two NPs with equal sizes, which may be attributable to the synthesis process. There were several factors that influenced NP growth not being realized in its entirety in all the NPs; therefore, the sizes measured varied within the particles containing the same type of metal.

3.2. FT-IR Spectroscopy. Shown below are IR spectra from which polymer structure characterization can be achieved. $\mathrm{HA}$ was analyzed in the middle or intermediate IR range (up to $4000 \mathrm{~cm}^{-1}$ ) to corroborate the presence of polymer in each of solid samples containing NPs of $\mathrm{Au}, \mathrm{Ag}, \mathrm{Cu}$, and AgPd. From these spectra, one can check for the presence of the main organic groups present in the molecule. In addition, spectroscopy in the far IR range (up to $400 \mathrm{~cm}^{-1}$ ) was performed on the samples of MNPs, making it possible to distinguish the main bonds where the MNPs are linked to the polymer and the presence of clusters or atomic groupings of the same metal (see Table 1). 
TABLE 2: HA and MNP bonds and their possible frequency bands.

\begin{tabular}{lcc}
\hline HA-metal & $\begin{array}{c}\text { Frequency of metal-oxygen } \\
\left(\mathrm{cm}^{-1}\right)\end{array}$ & $\begin{array}{c}\text { Frequency of metal (clusters) } \\
\left(\mathrm{cm}^{-1}\right)\end{array}$ \\
\hline HA-Au & 451,39 & 126,56 \\
HA-Ag & 444,72 & 186,72 \\
HA-Cu & 445,25 & 132,72 \\
HA-AgPd & 459,06 & 122,86 \\
\hline
\end{tabular}

TABle 3: Summary table of decomposition temperatures and mass losses of solid NPs of Au, Ag, Cu, and AgPd-2 alloy supported by HA.

\begin{tabular}{lcccccc}
\hline Solid & $\begin{array}{c}\text { Total mass } \\
(\mathrm{mg})\end{array}$ & $\begin{array}{c}\text { Decomposition } \\
\text { temperature }\left({ }^{\circ} \mathrm{C}\right)\end{array}$ & $\begin{array}{c}\text { Percentage of } \\
\text { mass loss }(\%)\end{array}$ & Mass loss $(\mathrm{mg})$ & $\begin{array}{c}\text { Residual loss temperature } \\
\left({ }^{\circ} \mathrm{C} \text {, approx. }\right)\end{array}$ & $\begin{array}{c}\text { Residual mass } \\
\text { percentage }(\%)\end{array}$ \\
\hline HA & 12,185 & 220,98 & 63,07 & 7,685 & 500 & 36,93 \\
HA-Au-2 & 11,568 & 217,94 & 73.89 & 8,547 & 500 & 26.11 \\
HA-Ag-2 & 6,269 & 217,80 & 76,87 & 4,819 & 550 & 23.16 \\
HA-Cu-2 & 5,264 & 218,72 & 72,01 & 3,791 & 550 & 27.99 \\
HA-AgPd-2 & 7,563 & 220,45 & 76,26 & 5,768 & 550 & 23.74 \\
\hline
\end{tabular}

TABLE 4: Inhibition of bacterial growth by films of metallic NPs supported by HA.

\begin{tabular}{lcccccccc}
\hline Films of MNPs & HA-Au-2 & HA-Au-3 & HA-Ag-2 & HA-Ag-3 & HA-Cu-2 & HA-Cu-3 & HA-AgPd-2 & HA-AgPd-3 \\
\hline S. aureus ATCC (25923) & $\mathrm{x}$ & $\mathrm{x}$ & $\mathrm{xx}$ & $\mathrm{xxx}$ & $\mathrm{xx}$ & $\mathrm{xx}$ & $\mathrm{xx}$ & $\mathrm{x}$ \\
S. epidermidis ATCC (122228) & $\mathrm{xx}$ & $\mathrm{xx}$ & $\mathrm{xx}$ & $\mathrm{xx}$ & $\mathrm{xx}$ & $\mathrm{xx}$ & $\mathrm{xx}$ & $\mathrm{x}$ \\
E. coli ATCC (25922) & $\mathrm{x}$ & $\mathrm{xx}$ & $\mathrm{xxx}$ & $\mathrm{xx}$ & $\mathrm{xx}$ & $\mathrm{xx}$ & $\mathrm{x}$ & $\mathrm{xx}$ \\
P. aeruginosa ATCC (27853) & $\mathrm{xx}$ & $\mathrm{xx}$ & $\mathrm{xxx}$ & $\mathrm{xxx}$ & $\mathrm{xx}$ & $\mathrm{xxx}$ & $\mathrm{xx}$ & $\mathrm{xx}$ \\
\hline
\end{tabular}

$(\mathrm{x}=$ no inhibition; $\mathrm{xx}=$ decreases growth; $\mathrm{xxx}=$ inhibits $)$.

To confirm the presence or absence of the major functional groups of HA as a polymer solid used to support NPs, it is not necessary to obtain an equal value in terms of frequency but rather to confirm that bands move only within similar ranges with a minimal difference. This difference between each solid sample containing a different metal arises from the metal causing the bands to behave similarly but not exhibit the same vibrations. The $3428 \mathrm{~cm}^{-1}$ bands correspond to the vibration of $-\mathrm{OH}$ bond stretching. The band at $2928 \mathrm{~cm}^{-1}$ is due to $-\mathrm{CH}$ bond stretching. At $1727 \mathrm{~cm}^{-1}$, the band corresponds to the absorption from $\mathrm{C}=\mathrm{O}$ double bond stretching, and the 1624 and $1625 \mathrm{~cm}^{-1}$ bands show absorption from the stretching of the $\mathrm{C}=\mathrm{C}$ double bonds or chelated groups in the case of Au-2.

3.3. Far FT-IR. Spectrum allows us to demonstrate the possible bonds between HA and the metal, which are concentrated around the metal-oxygen groups of hyaluronate (a monomer unit that interacts with metals) and the carbonyl of the glucuronic acid group, which displaces the band. Furthermore, the presence of bonds between clusters of atoms of the same metal is observed [38, 39]. Table 2 summarizes the far IR bands of different nanoclusters involved.

3.4. Thermogravimetric Analysis (TGA). The main objective of TGA is to demonstrate the stability of metallic solids in response to temperature changes. From the obtained scans, it is possible to determine the temperature of decomposition of a polymer and a polymer doped with MNPs and to obtain information on the percentage of mass loss of a sample, which can be used to determine which sample is more stable.

From the results in Table 3, it can be concluded than the average experimental decomposition temperature of the polymer supporting MNPs is $218.73^{\circ} \mathrm{C}$. On the other hand, the decomposition temperature of pure $\mathrm{HA}$ is around $220^{\circ} \mathrm{C}$ (shown in Figure 5). Similar result occurs with chitosan; a decrease in decomposition temperature is observed between pure and MNPs-doped polymer [40]. The observed values of percentage of mass loss are, with some degree of similarity, directly related to the loss in mass (in $\mathrm{mg}$ ) undergone by the solid samples. The residual mass percentage and temperature refer to the peak temperature at which mass is no longer lost as a result of increasing the temperature of the sample. The residual mass is between 23 and $27 \%$ for doped $\mathrm{HA}$, while the pure HA exhibit a residual mass of $36,93 \%$.

3.5. Bacteriological Assays. The results of the qualitative analysis are shown in Table 4 . In general, the highest activity was found in gels containing NPs of copper and silver, with both displaying activity against the four tested strains of bacteria.

Comparison of the results with the literature is challenging, mainly due to differences in the methodologies used and the polymer used as a support. Most of the work in this field uses chitosan as the polymer support. Chitosan is known to have antibacterial properties significantly different from those of HA, which has weak or no antibacterial activity depending on the tested microorganism [41]. Our results 


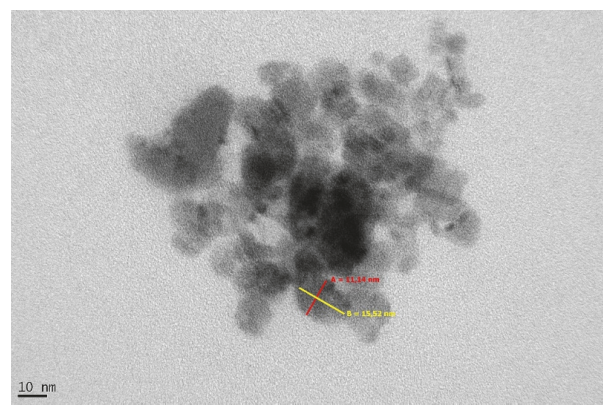

FIgURE 2: Copper cluster supported in HA. It is possible to observe single particles with average particle size of $13.33 \mathrm{~nm}$.

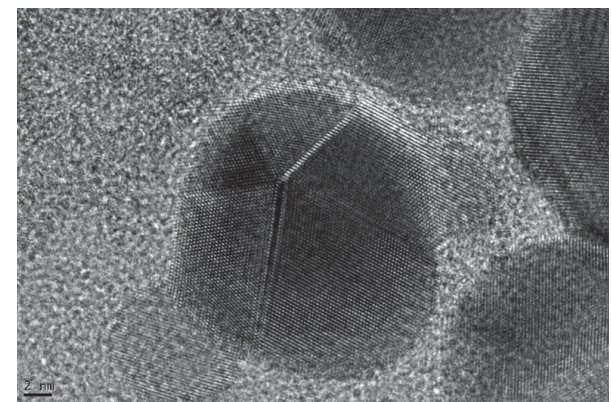

(a)

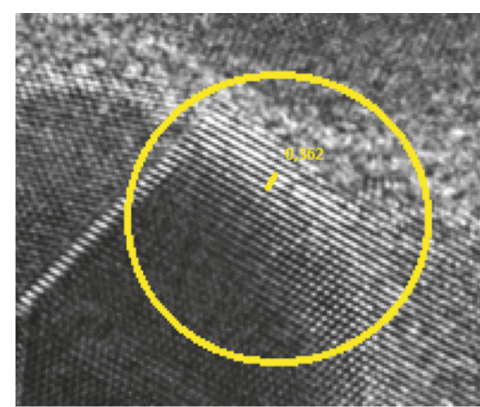

(b)

Figure 3: Two high-resolution micrographs of HA-AgPd (a). The interplanar distance is observed in (b).

show that strong antibacterial activity is achieved with NPs of copper and silver, while low activity is observed with gold and silver palladium. These results are consistent with the literature, which indicates that metals such as gold and platinum have low antibacterial activity [8]. Anisha et al. (2013) [42] used a matrix of chitosan/hyaluronic acid as support for silver nanoparticles and determined the antibacterial activity of the compound. They demonstrated that the mix was active against all the bacteria tested, including methicillin-resistant Staphylococcus aureus strains. These results are comparable with the result of this work. One study reports MIC values comparable to those obtained in this study for silver and copper, with values of $>0.395 \mathrm{mg} / \mathrm{ml}$ and $0.048 \mathrm{mg} / \mathrm{ml}$, respectively, against E. coli and $0.198-0.395$ and $0.048 \mathrm{mg} / \mathrm{ml}$, respectively, against $S$. aureus, values that are similar to the inhibition of bacteria growing on the films. This study shows a MIC for copper that is the same $(0.048 \mathrm{mg} / \mathrm{ml})$ against all the strains tested, which is less than half the value reported by Ruparelia et al. [8] for this metal; in the case of silver, the values are similar.

3.6. Bioassays in Rats. The toxicity tests were conducted in laboratory rats weighing $100 \mathrm{~g}$ that were separated into two groups, one experimental and the other a control, whose evaluation was performed after the solution was injected intraperitoneally at days 1 and 7. A blood sample of $0.5 \mathrm{ml}$ was taken to determine the hepatic biochemical parameters, including ALT, GGT, bilirubin, and albumin. After euthanasia, all hepatic and renal tissue was extracted for histopathologic analysis. This analysis was used to determine if the solutions of the MNPs supported on HA were sufficiently nontoxic to permit their use.
We find that the levels of ALT, GGT, and bilirubin measured at 14 days after intraperitoneal injection were normal in the group of animals injected at days 1 and 7 with $0.5 \mathrm{ml}$ of a $0.5 \%$ solution of $\mathrm{Au}, \mathrm{Ag}$, and $\mathrm{Cu}$ or AgPd-NPs supported by HA (see Figure 6).

There were no changes associated with hepatotoxicity after 14 days in all sampled groups since the liver functionality-specific enzymes and the levels of albumin and bilirubin synthesized were found to be within normal ranges. There were also no signs associated with damage to the hepatic or renal tissue in samples taken 14 days later after the euthanasia of each animal. With regard to the pathology, macroscopic analysis indicated that no mice belonging to the group injected with metals and HA had adhesions in their abdominal cavity. This finding leads to the conclusion that solution of MNPs supported in HA does not present high levels of toxicity; in fact, toxicity levels were within the normal ranges for continuous exposure.

\section{Conclusions}

Analyses were performed on metallic NPs of gold, silver, copper, and silver palladium (alloy) supported in the biopolymer $\mathrm{HA}$, which, despite not having antibacterial properties, acts as a favorable stabilizer of MNPs, allowing them to exhibit their unique properties, particularly their antibacterial abilities. These properties were evident from the first characterization analyses, such as HRTEM analysis, which showed MNPs located clearly in a spatial arrangement of atoms in the more stable (111) plane, as shown in Figure 2. Furthermore, the analyses allowed us to determine that the size of the MNPs 


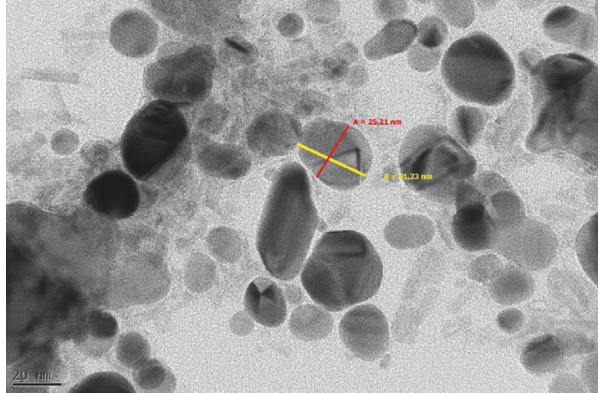

(a)

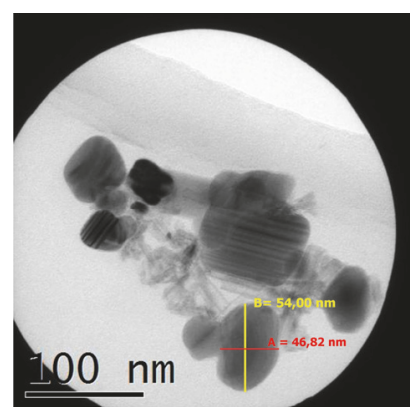

(b)

Figure 4: (a) Micrograph of HA-AgPd, average particle size of $33.22 \mathrm{~nm}$. (b) Micrograph of HA-Ag, average particle size of $50.41 \mathrm{~nm}$.

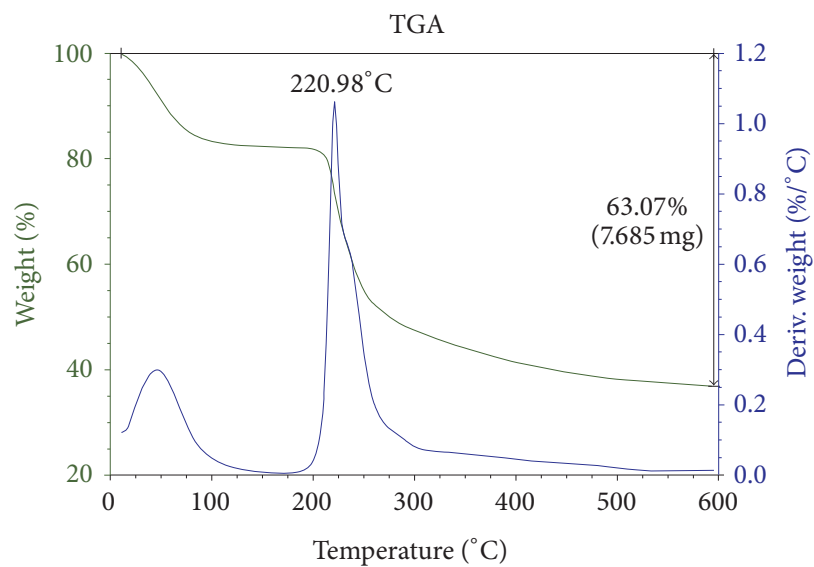

FIgURE 5: Thermogram of pure hyaluronic acid showing a decomposition temperature of $220^{\circ} \mathrm{C}$.

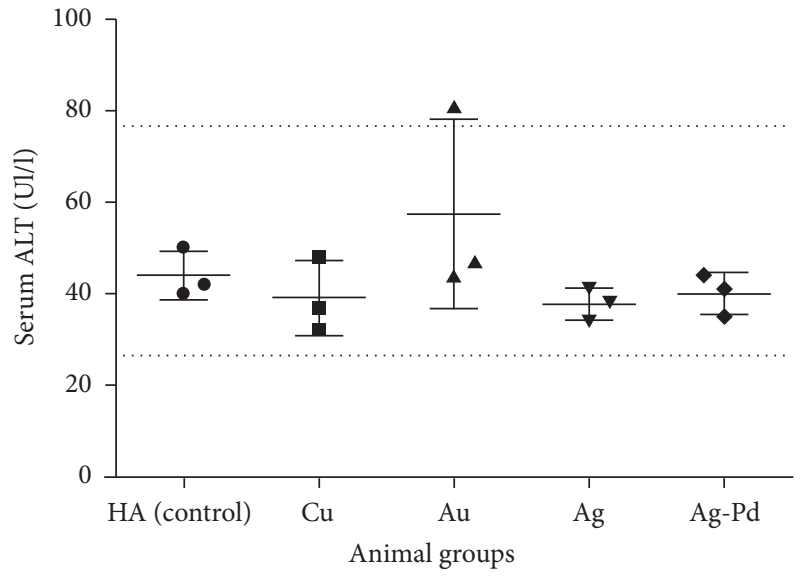

(a)

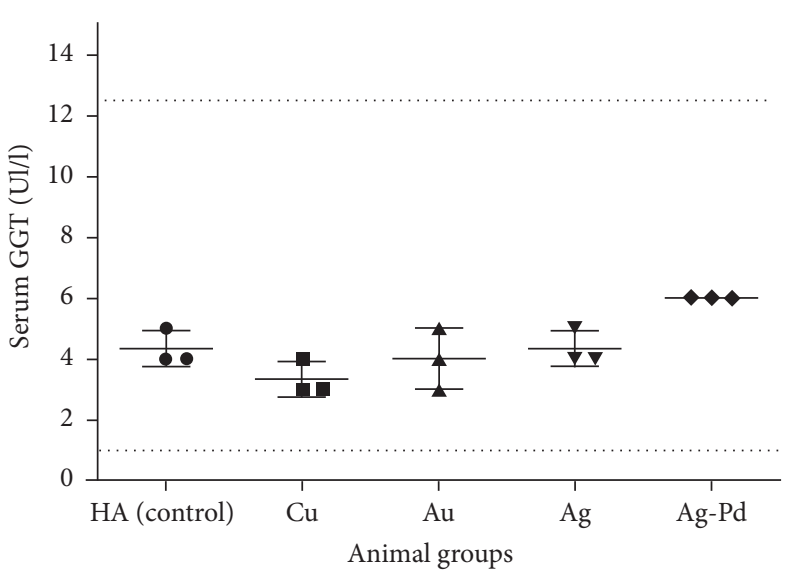

(b)

Figure 6: (a) Evaluation of ALT after the intraperitoneal injections at days 1 and 7 of $0.5 \mathrm{ml}$ of a $0.5 \%$ solution of $\mathrm{Au}, \mathrm{Ag}, \mathrm{Cu}, \mathrm{or} \mathrm{AgPd}-\mathrm{NPs}$ supported on HA. The enzymatic levels are close to the normal reference levels for this species. Dotted lines represent the normal reference range. (b) Evaluation of GGT after the intraperitoneal injection at days 1 and 7 of $0.5 \mathrm{ml}$ of a $0.5 \%$ solution of Au, Ag, Cu, or AgPd supported by HA. The enzymatic levels are close to the normal reference level for the species. Dotted lines represent the normal reference range.

was within the range of $10-50 \mathrm{~nm}$ and that differences in sizes existed between each of the different types of NPs, with AgNPs being the largest and CuNPs the smallest. We also characterized the presence of deformities and imperfections, such as nanotwins and strips of thickness in the AgNPs, attributable primarily to incomplete synthesis. Medium and far FT-IR analysis was used to determine that the $3428 \mathrm{~cm}^{-1}$ bands correspond to the vibration of the stretching of the $-\mathrm{OH}$ bond. The band at $2928 \mathrm{~cm}^{-1}$ is due to the stretching vibration of the $-\mathrm{CH}$ bond. A peak at $1727 \mathrm{~cm}^{-1}$ represents 
absorption in the $\mathrm{C}=\mathrm{O}$ double bond stretching band, among others. In the far IR, there were possible bonding interactions between HA and metal, which would be focused in the -Metal-O- groups of hyaluronate (a monomeric unit that interacts with metals) and the carbonyl group of glucuronic acid; these interactions cause the formation of bands. Furthermore, the presence of bonds between clusters of atoms of the same metal with values between 120 and $190 \mathrm{~cm}^{-1}$ was observed. TGA analysis determined that the temperature of decomposition for the system exhibits several peaks from 217 to $220^{\circ} \mathrm{C}$, values consistent with the literature, which indicates that HA macromolecules decompose at approximately $220^{\circ} \mathrm{C}$.

From these analyses, it is concluded that the use of HA as a stabilizing support offers the safety and capacity needed for its use in the preparation of medical dressings with MNPs. Although HA is being compared to other well-known biopolymers (e.g., chitosan) that have significant antibacterial properties, a greater likelihood of allergic reactions is ascribed to these polymers. Neutral HA, however, has no adverse reactions, is fully biocompatible, and is involved in tissue repair process. In addition to this factor, with the proven antibacterial properties of MNPs, we can fully recommend the use of these components for the development of an effective medical dressing. While the course of this work concluded with preclinical trials in animals (mice), it would be appropriate to continue this investigation with clinical trials of patients suffering from skin wounds and diseases.

\section{Conflicts of Interest}

The authors declare no competing financial interest.

\section{Acknowledgments}

The authors are grateful for the financial support of Conicyt, Fondecyt (Grant no. 1140025), and acknowledge Quitoquimica Ltda. for the use of their laboratory facilities.

\section{References}

[1] N. Scott and H. Chen, "Nanoscale science and engineering for agriculture and food systems," Industrial Biotechnology, vol. 9, no. 1, pp. 17-18, 2013.

[2] C. A. Mirkin, “The beginning of a small revolution," Small, vol. 1, no. 1, pp. 14-16, 2005.

[3] J. M. Campelo, D. Luna, R. Luque, J. M. Marinas, and A. A. Romero, "Sustainable preparation of supported metal nanoparticles and their applications in catalysis," ChemSusChem, vol. 2, no. 1, pp. 18-45, 2009.

[4] DL. Feldheim and CA. Foss, Eds., Metal Nanoparticles: Synthesis, Characterization, and Applications, CRC Press, and Applications, 2002.

[5] R. A. Freitas Jr., "What is nanomedicine?" Nanomedicine: Nanotechnology, Biology and Medicine, vol. 1, no. 1, pp. 2-9, 2005.

[6] E. Sadauskas, H. Wallin, M. Stoltenberg et al., "Kupffer cells are central in the removal of nanoparticles from the organism," Particle and Fibre Toxicology, vol. 4, article no. 10, 2007.

[7] A. Panáček, L. Kvítek, and R. Prucek, "Silver colloid nanoparticles: synthesis, characterization, and their antibacterial activity,"
The Journal of Physical Chemistry B, vol. 110, no. 33, pp. 1624816253, 2006.

[8] J. P. Ruparelia, A. K. Chatterjee, S. P. Duttagupta, and S. Mukherji, "Strain specificity in antimicrobial activity of silver and copper nanoparticles," Acta Biomaterialia, vol. 4, no. 3, pp. 707-716, 2008.

[9] W.-R. Li, X.-B. Xie, Q.-S. Shi, H.-Y. Zeng, Y.-S. Ou-Yang, and Y.-B. Chen, "Antibacterial activity and mechanism of silver nanoparticles on Escherichia coli," Applied Microbiology and Biotechnology, vol. 85, no. 4, pp. 1115-1122, 2010.

[10] V. Dhanalakshmi, T. R. Nimal, M. Sabitha, R. Biswas, and R. Jayakumar, "Skin and muscle permeating antibacterial nanoparticles for treating Staphylococcus aureus infected wounds," Journal of Biomedical Materials Research Part B: Applied Biomaterials, vol. 104, no. 4, pp. 797-807, 2016.

[11] E. E. Connor, J. Mwamuka, A. Gole, C. J. Murphy, and M. D. Wyatt, "Gold nanoparticles are taken up by human cells but do not cause acute cytotoxicity," Small, vol. 1, no. 3, pp. 325-327, 2005.

[12] R. Shukla, V. Bansal, M. Chaudhary, A. Basu, R. R. Bhonde, and M. Sastry, "Biocompatibility of gold nanoparticles and their endocytotic fate inside the cellular compartment: a microscopic overview," Langmuir, vol. 21, no. 23, pp. 10644-10654, 2005.

[13] P. Prema, P. A. Iniya, and G. Immanuel, "Microbial mediated synthesis, characterization, antibacterial and synergistic effect of gold nanoparticles using Klebsiella pneumoniae (MTCC4030)," RSC Advances, vol. 6, no. 6, pp. 4601-4607, 2016.

[14] J. Penders, M. Stolzoff, D. J. Hickey, M. Andersson, and T. J. Webster, "Shape-dependent antibacterial effects of noncytotoxic gold nanoparticles," International Journal of Nanomedicine, vol. 12, pp. 2457-2468, 2017.

[15] A. Avalos, AI. Haza, P. Morales, and P. Universidad, "Silver nanoparticles: applications and toxic risks to human health and the environment," Revista Complutense de Ciencias Veterinarias, vol. 7, p. 23, 2013, http://revistas.ucm.es/index.php/RCCV/ article/viewFile/43408/41203.

[16] R. Kohen and A. Nyska, "Oxidation of biological systems: oxidative stress phenomena, antioxidants, redox reactions, and methods for their quantification," Toxicologic Pathology, vol. 30, no. 6, pp. 620-650, 2002.

[17] M. Ahamed and M. K. J. Siddiqui, "Low level lead exposure and oxidative stress: current opinions," Clinica Chimica Acta, vol. 383, no. 1-2, pp. 57-64, 2007.

[18] M. J. Piao, K. A. Kang, I. K. Lee et al., "Silver nanoparticles induce oxidative cell damage in human liver cells through inhibition of reduced glutathione and induction of mitochondriainvolved apoptosis," Toxicology Letters, vol. 201, no. 1, pp. $92-$ 100, 2011.

[19] A. Lin, "Activation of the JNK signaling pathway: breaking the brake on apoptosis," BioEssays, vol. 25, no. 1, pp. 17-24, 2003.

[20] C. Carlson, S. M. Hussein, A. M. Schrand et al., "Unique cellular interaction of silver nanoparticles: size-dependent generation of reactive oxygen species," The Journal of Physical Chemistry B, vol. 112, no. 43, pp. 13608-13619, 2008.

[21] N. Miura and Y. Shinohara, "Cytotoxic effect and apoptosis induction by silver nanoparticles in HeLa cells," Biochemical and Biophysical Research Communications, vol. 390, no. 3, pp. 733-737, 2009.

[22] N. Hachicho, P. Hoffmann, K. Ahlert, and H. J. Heipieper, "Effect of silver nanoparticles and silver ions on growth and adaptive response mechanisms of Pseudomonas putida mt-2," FEMS Microbiology Letters, vol. 355, no. 1, pp. 71-77, 2014. 
[23] C. Beer, R. Foldbjerg, Y. Hayashi, D. S. Sutherland, and H. Autrup, "Toxicity of silver nanoparticles-Nanoparticle or silver ion?” Toxicology Letters, vol. 208, no. 3, pp. 286-292, 2012.

[24] C. Gonnelli, F. Galardi, and R. Gabbrielli, "Nickel and copper tolerance and toxicity in three Tuscan populations of Silene paradoxa," Physiologia Plantarum, vol. 113, no. 4, pp. 507-514, 2001.

[25] T. C. Hoang and S. J. Klaine, "Influence of organism age on metal toxicity to Daphnia magna," Environmental Toxicology and Chemistry, vol. 26, no. 6, pp. 1198-1204, 2007.

[26] M. Valodkar, P. S. Rathore, R. N. Jadeja, M. Thounaojam, R. V. Devkar, and S. Thakore, "Cytotoxicity evaluation and antimicrobial studies of starch capped water soluble copper nanoparticles," Journal of Hazardous Materials, vol. 201-202, pp. 244-249, 2012.

[27] C. Cruzat Contreras, O. Peña, M. F. Meléndrez, J. DíazVisurraga, and G. Cárdenas, "Synthesis, characterization and properties of magnetic colloids supported on chitosan," Colloid and Polymer Science, vol. 289, no. 1, pp. 21-31, 2011.

[28] C. Raymond Rowe, P. J. Sheskey, and M. E. Quinn, Handbook of Pharmaceutical Excipients, Pharmaceutical Press and American Pharmacists Association, Washington, USA, 6th edition, 2009.

[29] K. Imai, T. Shirai, M. Akiyama et al., "Effects on ES cell differentiation on the corroded Surface of four silver alloys for dental use," Journal of Oral Tissue Engineering, vol. 14, pp. 3440, 2016.

[30] A. Milheiro, J. Muris, C. J. Kleverlaan, and A. J. Feilzer, "Influence of shape and finishing on the corrosion of palladium-based dental alloys," The Journal of Advanced Prosthodontics, vol. 7, no. 1, pp. 56-61, 2015.

[31] J. C. Wataha, "Biocompatibility of dental casting alloys: a review," Journal of Prosthetic Dentistry, vol. 83, no. 2, pp. 223234, 2000.

[32] W. Y. J. Chen and G. Abatangelo, "Functions of hyaluronan in wound repair," Wound Repair and Regeneration, vol. 7, no. 2, pp. 79-89, 1999.

[33] G. Weindl, M. Schaller, M. Schäfer-Korting, and H. C. Korting, "Hyaluronic acid in the treatment and prevention of skin diseases: molecular biological, pharmaceutical and clinical aspects," Skin Pharmacology and Physiology, vol. 17, no. 5, pp. 207-213, 2004.

[34] M. Rai, A. Yadav, and A. Gade, "Silver nanoparticles as a new generation of antimicrobials," Biotechnology Advances, vol. 27, no. 1, pp. 76-83, 2009.

[35] C. Cruzat, Synthesis and characterization of Chitosan-supported metal nanoparticles. Thesis submitted to the University of Concepci $n$ in partial fulfilment of the requirements to qualify for the degree of Ph.D. in chemistry [Ph.D. thesis], Chile, 2010.

[36] G. Cárdenas-Triviño, "Chemical Reactions at Nanometal Particles," Journal of the Chilean Chemical Society, vol. 50, no. 3, 2005.

[37] G. Cárdenas Triviño, O. Godoy Guzmán, and G. Contreras, "Dysprosium Colloids Prepared in Polar Organic Solvents," Journal of the Chilean Chemical Society, vol. 54, no. 1, 2009.

[38] G. Kliche and Z. V. Popovic, "Far-infrared spectroscopic investigations on CuO," Physical Review B: Condensed Matter and Materials Physics, vol. 42, no. 16, pp. 10060-10066, 1990.

[39] M. R. H. Siddiqui, S. F. Adil, M. E. Assal, R. Ali, and A. AlWarthan, "Synthesis and characterization of silver oxide and silver chloride nanoparticles with high thermal stability," Asian Journal of Chemistry, vol. 25, no. 6, pp. 3405-3409, 2013.
[40] M. Heuser and G. Cárdenas, "Chitosan-copper paint types as antifouling," Journal of the Chilean Chemical Society, vol. 59, no. 2, pp. 2415-2419, 2014.

[41] M. Bračič, L. Pérez, R. I. Martinez-Pardo et al., "A novel synergistic formulation between a cationic surfactant from lysine and hyaluronic acid as an antimicrobial coating for advanced cellulose materials," Cellulose, vol. 21, no. 4, pp. 26472663, 2014.

[42] B. S. Anisha, R. Biswas, K. P. Chennazhi, and R. Jayakumar, "Chitosan-hyaluronic acid/nano silver composite sponges for drug resistant bacteria infected diabetic wounds," International Journal of Biological Macromolecules, vol. 62, pp. 310-320, 2013. 

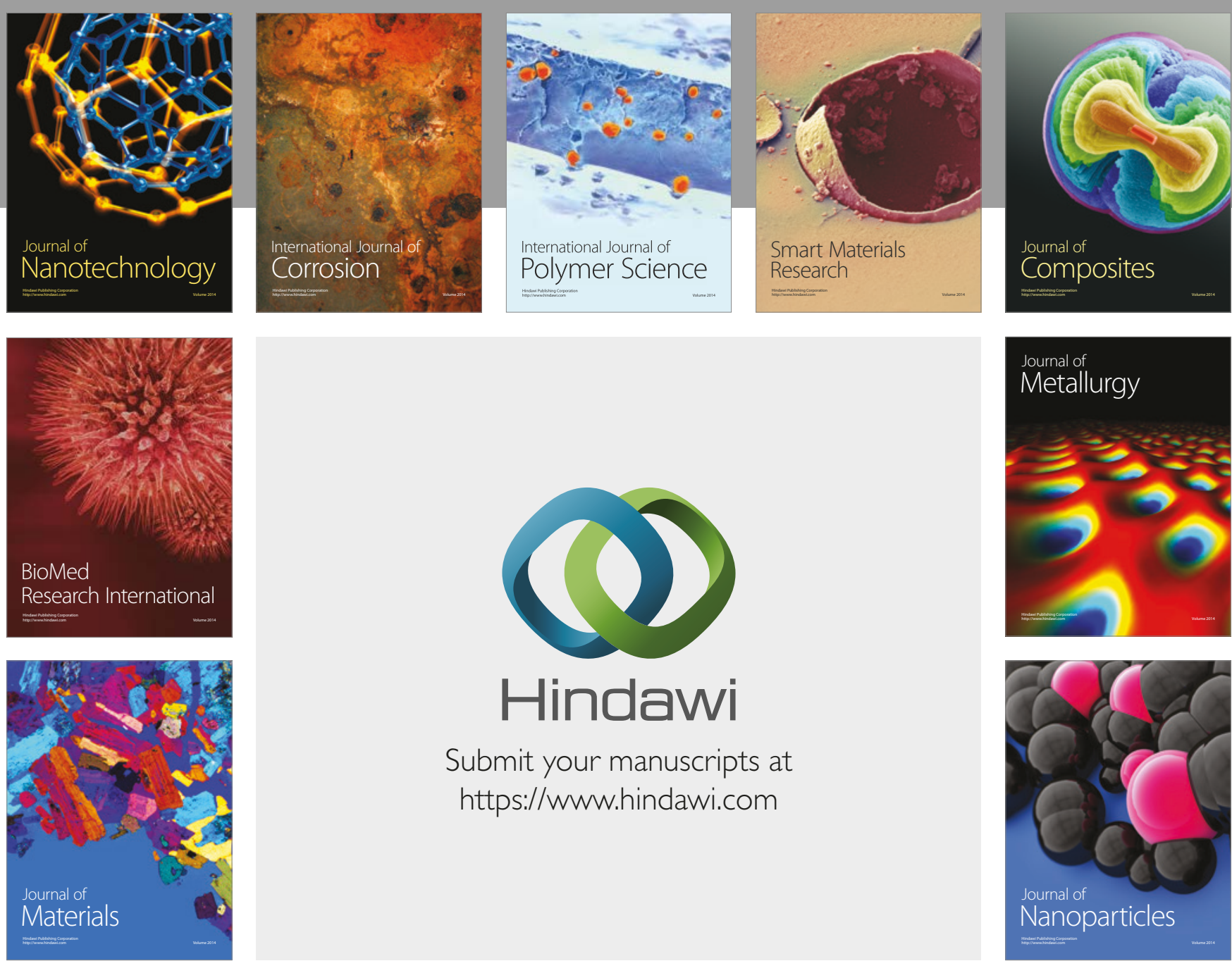

\section{Hindawi}

Submit your manuscripts at

https://www.hindawi.com
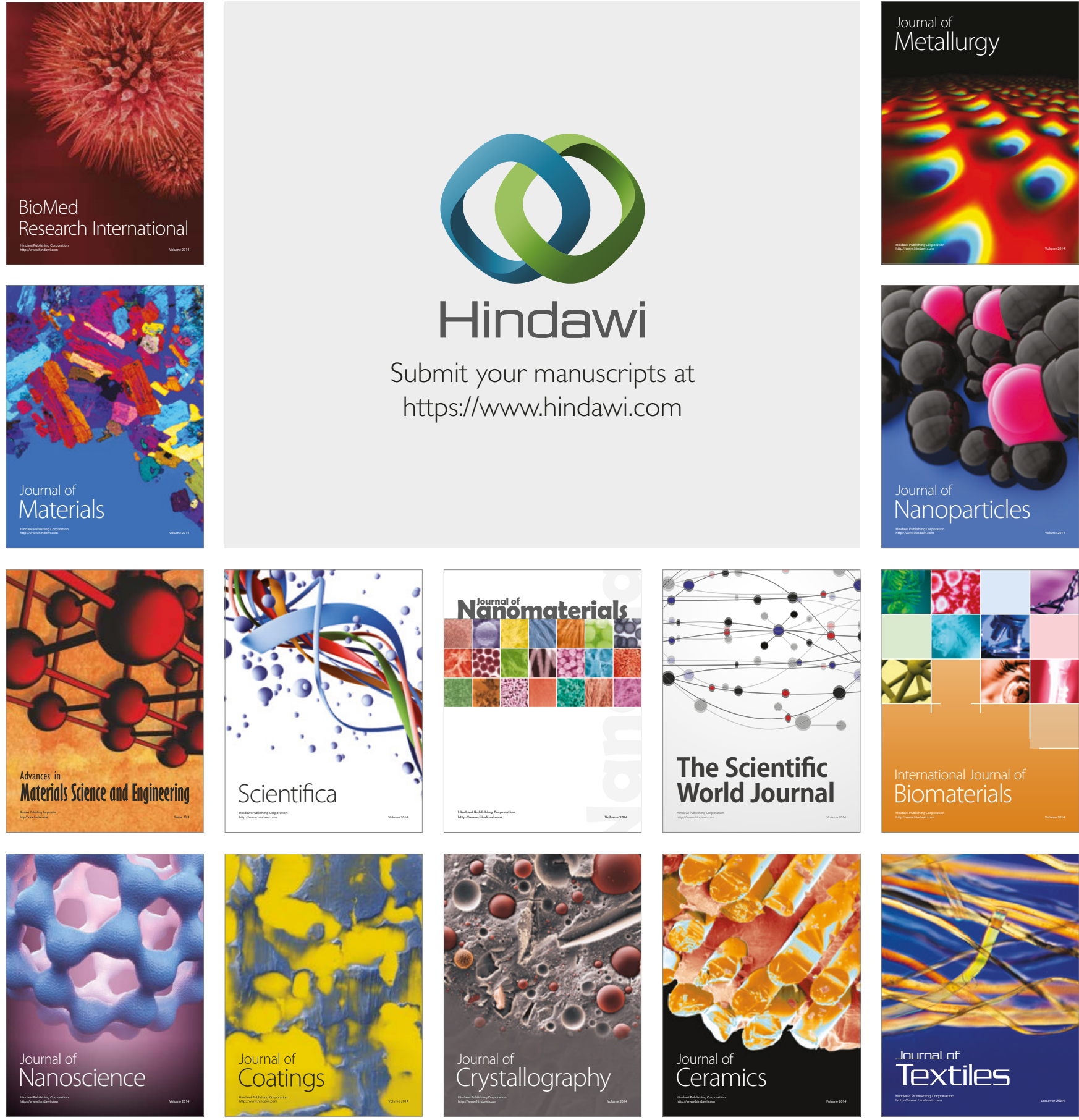

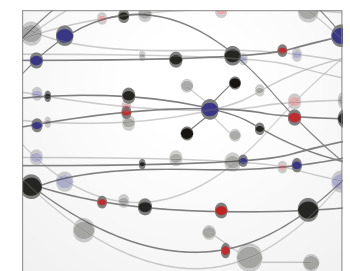

The Scientific World Journal
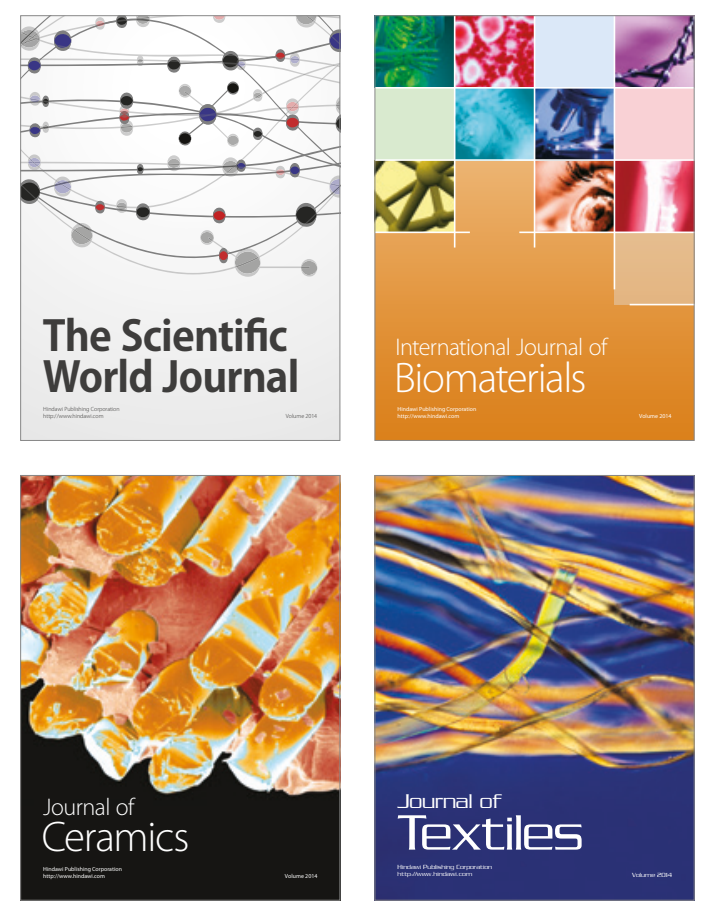